\title{
Review on License plate recognition algorithms in images and video
}

\author{
${ }^{1}$ Faisal Ghazi. Mohammed, ${ }^{2}$ Nada Hassan Jasem \\ ${ }^{1}$ Department of Remote Sensing and Geographic Information's \\ ${ }^{2}$ College of science, University of Baghdad, Baghdad, Iraq
}

\author{
Article Type: Subject Review
}

\begin{abstract}
It is possible to identify the existing license plate (LPR) pictures or videos depending on the algorithms used and in general it is possible that the algorithms consist of three steps in terms of processing are 1) extracting the part of the license plate; 2) manufacture of the license plate section. and 3) recognition of each character. The process is difficult due to the diversity of the panels' formats, as well as the lack of sufficient and uniform lighting during image acquisition, so it will be constrained under conditions such as fixed lighting, speed, specific roads, and other conditions.

Several LPR technologies were developed in images and videos. This paper is a review of the authors work in this field and extracting the best results that the researchers reached to evaluate the LPR algorithm.
\end{abstract}

Key Word: Automatic Plate Number Recognition, Segmentation, License Plate Detection (LP), License Plate Recognition.

\section{INTRODUCTION}

The computer was implemented to handle textual data and solve everyday problems. Where the optical device was used to enter the inputs in terms of its application in several fields, including medical, security, control, control and engineering. As a result of the computer's ability to process and produce images in a meaningful way that has become more popular, therefore, image processing technology has been adopted in managing most of the parking system, various vehicles can be accessed in restricted areas, traffic control of cars, and the collection of various electronic highway graphics. For this purpose, the cameras were used to capture the license plate numbers and process it on the computer and the result of the processing is the license plate number in text form, and the result that is the output is used to identify the vehicle, and the license [1]. In this paper, a review of authors who worked on the license plate research for vehicles using image processing is reviewed. The framework of this research has been adapted from previous studies.

\section{LITERATURE SURVEY}

During the past two decades, many research efforts have been made to develop a methodology for identifying the license plate. In the following, some of the published work is presented, the focus will be on the methodology used for implementing those LPR systems. Also, their related weakness, virtues, in this paper, we will discuss some of the authors who have worked on the category of how to handle licenses for the board

- $\quad$ The authors, in this paper [2] presented how to identify license plates for portable vehicles, depending on a video camera not installed in the car, where the proposed method was used to take pictures of the car and address the identification of a license plate where in this work was first to discover the location of the bark lights of the captured image and then reveal the license plate The Black Top-Hat method was also used to enhance the level of separation of license plate characters. Experiments have shown that the system can take the image of the vehicle and reveal the license plate and identify it effectively and quickly, whether in the day or at night or in a complex environment.

- In this paper, the authors mohsin and et al[3], presented a method to identify the Iraqi license plates, depending on the ELMAN Neural network, one for the numbers and the other for the names of the provinces. In the process of processing, both the Median filter, Sobel operator and image banalization were used. In image, segmentation was used for vertical and horizontal projection and a set of images was tested Their number reached approximately (21) images, and the process achieved a success rate of $(85 \%, 76 \%)$, respectively. 
- In this paper, the author XIN LI [4], provides a way to develop a license plate discovery based on an SVM workbook with the HOG feature. The system works by searching the framework based on different scales based on the HOG feature using analysis using SVM and the surrounding boxes can be determined using Mean Shift. The performance and analysis of the HOG algorithm were compared with different cell and block sizes, the results show that changes in lighting, license plate patterns, license plate perspective, and background complexity for this method are relatively insensitive. Quantitative analysis was also performed on the Caltech dataset (1999), and an acceptable accuracy rate of $96.0 \%$ was achieved. This method demonstrates it can help with the traditional chart drop method to deal with some critical situations such as low contrast or oblique position. Character recognition was handled in two ways. The One VsAll and DigitOrLetter policy confusion matrices were shown, and their recognition rate was conscious. However, further improvement of the algorithm is required to achieve better performance.

- In this paper, the authors Deb and et al [5], introduced a framework that can overcome the failure of detecting LPs when the vehicle and their license plates have the same color (e.g. a white car has a white license plate). Also, this paper discussed the tilt correction of vehicle license plate. In the proposed framework, the license vehicle image will be converted to HSI color. Panel color information is used to detect candidate areas. Then the engineering properties of the LP are extracted for classification purposes and are properties such as area, square circumference, and aspect ratio. It is used to solve the failure to disclose the limits of the license plates, the modified recursive tag algorithm, when the compound and the color of the LPs have the same colors. According to the Least Square Fitting with Offsets Vertically (LSFPO), the LP area is equipped with a straight line. After obtaining the slope of the line, the required rotation angle for low pressure is estimated. Then, to correct the slope in the horizontal direction the entire image is rotated by the angle of rotation. Tilt correction in the vertical direction is achieved by the reverse affine transformation. Hough lines intersection is used to detect LP filter boundaries and heads. Finally, the letters of the LP regions are recognized. However, the suggested method failed when the blur movement appears in the input image. A set of 200 samples of Korean LP images are used.

- In this paper, the authors Cika, and et al [6], proposed a system for detecting and recognizing the characters and numbers of Czech Republic LPs. The system consists of a number of units that are dependent on one another. The modules used are: image enhancement (contrast expansion), luminance conversion (RGB to YUV) for gray image, threshold for binary image, segmentation of regions, and evaluation of regions (for selecting rectangular objects or rectangular shape). Then the image is rotated, passed through OCR, and finally in the database the recognized license plates are compared. The authors indicated that the proposed parking system was appropriate. 50 samples were used. The success rate of achieving success was $88 \%$.

- In this paper, the authors Muhammad and others [7]. Introduced the LPR system where a Gaussian filter was used to remove noise, where it is converted to a grayscale image, graph equation, and a vertical Cobel was used. A medium filter and histogram equation was used to enhance contrast and rotation by converting Hough, grape line detection, Otsu diode design, and vertical depiction based on the vertical projection graph in a fractionation process to eliminate noise. The system was tested by taking (200) pictures and the result was accurate translation is $91 \%$, segmentation is $97 \%$ and recognition is 94 .

- In this paper, the authors Ghofrani and Rasooli [8], introduced a system for license plate detection and recognition for Iranian private cars. The authors of the paper believe that the proposed system can be used for the other two classes (i.e. public and governmental cars). The proposed system first extracts vertical edges, then, it turns to mark candidate regions. These regions are determined via two steps: moving windows and checking the aspect ratio feature. The regions were candidate as being the license plate are passed through elements analyser in order to detect the license plate accurately. Then, the required rotation angle is estimated and rotation adjustment is done. For character recognition 25 features are derived from the character's zones (i.e., character region is divided into four equal parts), these are considered as input to the two artificial neural network classifiers (one for characters and the other for numbers). A set of 200 images were used. The test results indicated that the proposed method works properly independent of distance, rotation, and deformed LP. In addition, the system works well even when more than one car may exist in the image. The attained LP detection rate was $91 \%$. LP recognition rate was $92.2 \%$.

- The authors Khalid W. Maglad [9], presented in this paper a four-stage VLPR system: first pre-treatment where it included an image with grayscale that turns into a dual image, detection of the edge of the Sobel, the process of stretching, filling the holes through the flood filling algorithm, and noise removal. Secondly, the phase detection of the neural network and the radial basis function (RBF) were used to detect the accuracy of the LP, thirdly, OTSU segmentation was used to create a binary image, remove noise using a medium filter, CCL was used and finally the use of the RBF neural network was recognized. System and accuracy were tested for translation is $95 \%$, segmentation is $99 \%$, and recognition is $91 \%$.

- In this paper, the author Nada N. K[10], This paper deals with the Iraqi LPR method that was formed from three stages: the first stage of treatment, the proposed color convergence process was used for the binary coding image, the image size was reduced by using the mean method and the seed filling algorithm was used to segment the image. In the second stage, the localization features extracted for each Piece, fill in the LP slots based on the filing algorithm, the LP was rotated around its center, and the converter transformation was applied. And lastly in the estimation phase, which consists of two steps: segmentation of LP characters using the algorithm of seed packing and letters that are recognized based on two methods: instant distribution and local 
density. For black LPs, localization rates reached $60.74 \%$, and for white LPs, they reached $89.51 \%$, using the simultaneous method, the identification rates reached $63.52 \%$, while using the local density distribution method reached $98.09 \%$.

- In this paper, the authors Furat N, Taw feeq and et al [11], presented a method to control the opening of the door gate based on the license numbers in Iraq. The proposed system consists of four sections. In the first section, taking pictures, a camera is used to take a picture in the car that is placed on the door gate and at a specific distance from the front of the car to be processed by our system. Then cut the license plate by matching the license plate in the image to the standard plate, the edges are detected and executed in the Segmentation stage. Finally, letters are identified, and this is done by comparing letters and template numbers used in the Iraqi plate. The results showed an accurate performance of $93.33 \%$.

- In this paper, the author Emad.M. Abod [12], presented a method for the Iraqi license plate that tracks vehicles in real time, and the system is summarized in five phases, the first stage being represented. It is pre-processing, as the image is optimized using a number of algorithms, and the second stage is image capture based on modern embedded systems. In the third stage localization, select the combination method for locating the LP in the image. In the fourth stage of fragmentation, where at this stage to extract the image of letters / letters depending on the use of several methods and a proposed strategy. Getting to know, he suggested using two solutions: Moment variables with correlation and MCA, one dependent on feature extraction and the other dependent on associative memory. In the fifth stage of traceability, to locate the vehicle according to the satellite navigation system where it is suggested to use latitude and longitude coordinates. In this work, a picture (217) of the German-Iraqi painting was taken in various environmental conditions. The results and tests showed the following: (85\%) of the Arabization phase were identified and tracked, it is a segmentation phase and a recognition phase using moments (92\%) with training and (78\%) without training. The second way to learn about the Multi-Connect Engineering (MCA) was achieved (89\%) with thinning and (74\%) without thinning. The proportion of the compounds correctly identified by the proposed LPR system (80\%). The proposed real-time system was implemented, which achieved real-time systems objectives averaged (3) per second from all stages of the proposed LPR system.

- $\quad$.In this paper, the authors Eyed I. Abbas et al [13], presented system consists of two main parts: the first is a practical implementation of how to take an automatically snapshot for cars passes, this was done by two sensors connected with each other and interfaced with a USB camera. The second part includes four basic stages: The first stage is image preprocessing which involves image normalization and RGB to gray image conversion. Second stage is detection of a possible license plate using edge detection technique and extracts these LP using region growing technique. Third stage is alphanumeric character segmentation to isolate each character, numbers and words of the license plate using Otsu's and Hough transforms technique. The last stage recognized the alphanumeric character and words by correlation template matching. the detection rates reach to $95 \%$ and the recognition rate reach to $98.245 \%$.

- The authors Safaa. S. Omran [14], in this paper produced the system is designed to identify Iraqi license plates. This research consists of the following steps are: locating the LP from the car image, distinguish between the three types of Iraqi LP: (In this part distinguish between the three patterns Iraqi license plates are taking place), in Pre-processing step the threshold using Otsu Method and morphological processes to promote LP picture, the License Plate Divide into three parts are number, province and type .in last step has been used OCR's method Numbers, letters and words recognition. The system is tested on 40 samples of pictures. Finally, the rate was $87.5 \%$ for the extraction plate and $85.7 \%$ for for accurate recognition; giving a general order performance recognition rate $86.6 \%$.

- In this paper, the authors Jia Wang1, et al [15], presented a plate number localization algorithm where he used a new method called Secondary Positioning (SP) that was proposed and tested on the locally acquired dataset. Where in the first stage the rough position of the plate number was determined by searching in the red light areas in the HSV color space, and in the second stage an accurate position of the plate number is determined by knowing the vertical edge of the plate number. Template matching implemented for individual characters includes a calculated correction factor between templates and image testing. The test data set includes two subsets of our local plate numbers, which are 120 images used to localize the plate number, and 80 images to identify the plate number. The accuracy obtained from localization and identification of plate number is about $75 \%$ and $70 \%$, respectively.

- In this paper, the author Ghassan K.Ali [16] ,presented a method for developing a system to identify the new Iraqi license plate, and the system used a number of stages to implement it: first obtaining images, secondly discovering the license plate based on Viola and Jones Framework, and thirdly processing the image board, at this stage there are many processes (Gray Conversion, remove noise used to filter the medium, and convert binary images). Fourth, retail. In this step, divide the digital image into areas or groups of pixels that represent different objects in the image, and finally, the template matching application algorithm to identify sections of the plate image. The accuracy of this system is about $88 \%$.

- The authors Ira Kusumadewi, et al[17], in this paper have provided a method for identifying the license plate number using the template matching method and wrapping around templates. The number pad includes a number of letters and numbers that are an object in an image. In order to recognize the letters, the number plate object in the image must be created early, normalized and segmented. A circumference algorithm is used to separate each letter. Therefore, to test this study to reveal Indonesian car license plates, I used a mixture of matching molds and surrounding box styles. Whose accuracy reaches $80 \%$. 
- The authors jianzong wang, et al [18], presented solution for recognizing LP photographs in China using deep convolution neural network (DCNN) and recurrent neural network (RNN) models. It has the function of DCNN. The LP is found and a description of the LP is extracted after the correction process. Then we ran the RNN model to encryption deep features into letters without segmentation letters. System accuracy was 92.32 and 91.89 for vehicle accident data sets collected in the landscape and 92.88 and 92.09 for the Caltech Cars data set.

\section{PERFORMANCE ANALYSIS FOR LICENSE PLATE RECOGNITION METHOD}

In this section, we will describe a summary of the researchers' achievement in terms of performance analysis of the method of identifying the license plate that represents the infrastructure of the knowledge base at the present time, as well as the characteristics of a panel and how it is classified, and this will be explained in Table (1).

Table 1. Performance Analysis for License Plate Recognition Method

\begin{tabular}{|c|c|c|c|}
\hline $\begin{array}{l}\text { Sl. } \\
\text { No }\end{array}$ & The number of stages used & $\begin{array}{l}\text { the method using for recognizing } \\
\text { license plates. }\end{array}$ & Result Accuracy \\
\hline 1 & $\begin{array}{l}\text { The number of stages used } \\
\text { are three }\end{array}$ & $\begin{array}{l}\text { 1) Detection stage. } \\
\text { 2) Segmentation. } \\
\text { 3) Recognition, }\end{array}$ & $\begin{array}{l}\text { Detection is }(95.33 \%,) \text {, } \\
\text { segmentation is }(95.31 \%) \\
\text { and recognition is } 97.43 \%)\end{array}$ \\
\hline 2 & $\begin{array}{l}\text { The number of stages used } \\
\text { are four }\end{array}$ & $\begin{array}{l}\text { 1) image acquisition. } \\
\text { 2)preprocessing } \\
\text { 3) segmentation } \\
\text { 4) recognition }\end{array}$ & $\begin{array}{l}\text { it reaches to } 85 \% \text { correct } \\
\text { segmentation } \\
\text { it reaches to } 76 \% \text { correct } \\
\text { recognition for } 21 \text { samples }\end{array}$ \\
\hline 3 & $\begin{array}{l}\text { The number of stages used } \\
\text { are three }\end{array}$ & $\begin{array}{l}\text { 1) Detection, } \\
\text { 2) Segmentation } \\
\text { 3) Recognition }\end{array}$ & $\begin{array}{c}\text { it reaches to } \\
96.0 \%\end{array}$ \\
\hline 4 & $\begin{array}{l}\text { The number of stages used } \\
\text { are three }\end{array}$ & $\begin{array}{l}\text { 1) Detection stage. } \\
\text { 2) Segmentation. } \\
\text { 3) Recognition }\end{array}$ & it reaches to $96 \%$ \\
\hline 5 & $\begin{array}{l}\text { The number of stages used } \\
\text { are four }\end{array}$ & $\begin{array}{l}\text { 1) Image enhancement } \\
\text { 2) luminance transformation (RGB } \\
\text { to YUV) to get the gray image. } \\
\text { 3) Thresholding to get the binary } \\
\text { image. } \\
\text { 4) Image segmentation }\end{array}$ & it reaches to $88 \%$ \\
\hline 6 & $\begin{array}{l}\text { The number of stages used } \\
\text { are three }\end{array}$ & $\begin{array}{l}\text { 1) Translation } \\
\text { 2) Image enhancement }\end{array}$ & $\begin{array}{l}\text { translation is } 91 \%, \\
\text { segmentation is } 97 \% \text { and } \\
\text { recognition is } 94,\end{array}$ \\
\hline
\end{tabular}


International Journal of Engineering Research And Advanced Technology, Vol.6, Issue 2, February-2020

\begin{tabular}{|c|c|c|c|}
\hline & & 3) Recognition & \\
\hline 7 & $\begin{array}{l}\text { The number of stages used } \\
\text { are two }\end{array}$ & $\begin{array}{l}\text { 1) Detection stage. } \\
\text { 2) Recognition }\end{array}$ & $\begin{array}{l}\text { The attained LP detection } \\
\text { rate was } 91 \% \text { LP } \\
\text { recognition rate was } \\
92.2 \% \text {. }\end{array}$ \\
\hline 8 & $\begin{array}{l}\text { The number of stages used } \\
\text { are four }\end{array}$ & $\begin{array}{l}\text { 1)translation. } \\
\text { 2) Detection stage } \\
\text { 3) segmentation. } \\
\text { 4) recognition. }\end{array}$ & $\begin{array}{l}\text { System and accuracy } \\
\text { (translation is } 95 \% \text {, } \\
\text { segmentation is } 99 \% \text { and } \\
\text { recognition is } 91 \% \text { ) }\end{array}$ \\
\hline 9 & $\begin{array}{l}\text { The number of stages used } \\
\text { are three }\end{array}$ & $\begin{array}{l}\text { 1)Preprocessing. } \\
\text { 2) localization. } \\
\text { 3) and recognition. }\end{array}$ & it reaches to $\% 98.09$ \\
\hline 10 & $\begin{array}{l}\text { The number of stages used } \\
\text { are four }\end{array}$ & $\begin{array}{l}\text { 1) Take pictures.. } \\
\text { 2) Crop license plate.. } \\
\text { 3) character segmentation. } \\
\text { 4)character recognition }\end{array}$ & $\begin{array}{l}\text { accurate performance of } \\
93.33 \% \text {. }\end{array}$ \\
\hline 11 & $\begin{array}{l}\text { The number of stages used } \\
\text { are five }\end{array}$ & $\begin{array}{l}\text { 1) Preprocessing stage. } \\
\text { 2) localization stage. } \\
\text { 3) Segmentation stage. } \\
\text { 4) In recognition stage } \\
\text { 5) Tracking stage }\end{array}$ & $\begin{array}{l}\text { - The recognition } \\
\text { and the tracking } \\
\text { reached }(85 \%) \text {. } \\
\text { - localization } \\
\text { stage, (94\%) } \\
\text { - It is a } \\
\text { segmentation } \\
\text { phase and a } \\
\text { recognition phase } \\
\text { using moments } \\
(92 \%) \text { with } \\
\text { training and } \\
(78 \%) \text { without } \\
\text { training. } \\
\text { Recognition is } \\
\text { Multi-Connect } \\
\text { Architecture } \\
\text { (MCA) achieved } \\
(89 \%) \quad \text { with } \\
\text { thinning and } \\
\text { (74\%) without } \\
\text { thinning. } \\
\text { Ratio of vehicles }\end{array}$ \\
\hline
\end{tabular}




\begin{tabular}{|c|c|c|c|}
\hline & & & $\begin{array}{l}\text { that have been } \\
\text { correctly } \\
\text { recognition them } \\
\text { by the LPR } \\
\text { proposed system } \\
\text { were }(80 \%) \text {. }\end{array}$ \\
\hline 12 & $\begin{array}{l}\text { The number of stages used } \\
\text { are four }\end{array}$ & $\begin{array}{l}\text { 1)Image preprocessing. } \\
\text { 2)Detection stage. } \\
\text { 3) Segmentation. } \\
\text { 4) Recognition }\end{array}$ & $\begin{array}{l}\text { - The detection rates } \\
\text { reach to } 95 \% \text { and the } \\
\text { recognition rate reach to } \\
98.245 \% \text {. }\end{array}$ \\
\hline 13 & $\begin{array}{l}\text { The number of stages used } \\
\text { are five }\end{array}$ & $\begin{array}{l}\text { 1) Determine the site panel portion or } \\
\text { license plate detection (LPD) } \\
\text { 2) Discrimination of three types of } \\
\text { Iraqi LP } \\
\text { 3) Pre-processing. } \\
\text { 4) License plate character segmentation } \\
\text { (LPCS) } \\
\text { 5) Optical character recognition method }\end{array}$ & $\begin{array}{l}\text { - } 87.5 \% \text { proven to } \\
\text { extract the plate } \\
\text { region. } \\
\text { - The accuracy of } \\
\text { this paper proved } \\
\text { to be } 85.7 \% \text { of } \\
\text { the unit of } \\
\text { recognition. } \\
\text { - The recognition } \\
\text { rate for the } \\
\text { overall } \\
\text { performance of } \\
\text { the system is } \\
86.6 \% \text {. }\end{array}$ \\
\hline 14 & $\begin{array}{l}\text { The number of stages used } \\
\text { are two }\end{array}$ & $\begin{array}{l}\text { 1) localization } \\
\text { 2) And recognition }\end{array}$ & $\begin{array}{l}\text { - The accuracy } \\
\text { obtained from localization } \\
\text { is } 75 \% \text { and identification } \\
\text { of plate number is } 70 \% \text {. }\end{array}$ \\
\hline 15 & $\begin{array}{l}\text { The number of stages used } \\
\text { are four }\end{array}$ & $\begin{array}{l}\text { 1) image acquisition. } \\
\text { 2)preprocessing } \\
\text { 3) segmentation } \\
\text { 4) recognition }\end{array}$ & $\begin{array}{c}\text { - The accuracy of this } \\
\text { system is about } 88 \% \text {. }\end{array}$ \\
\hline 16 & $\begin{array}{l}\text { The number of stages used } \\
\text { are two }\end{array}$ & $\begin{array}{l}\text { 1)Normalized } \\
\text { 2) Segmented to recognize the character }\end{array}$ & $\begin{array}{l}\text { - the accuracy reaches } \\
80 \% \text {. }\end{array}$ \\
\hline 17 & $\begin{array}{l}\text { The number of stages used } \\
\text { are two }\end{array}$ & $\begin{array}{l}\text { 1) Deep convolution neural } \\
\text { network (DCNN) } \\
\text { 2) Recurrent neural network } \\
\text { (RNN) models }\end{array}$ & $\begin{array}{l}\text { - } 92.32 \text { and } 91.89 \\
\text { represent samples of } \\
\text { data sets collected in } \\
\text { in the natural scene } \\
\text { - } 92.88 \text { and } 92.09 \text { data } \\
\text { sets for Caltech Cars. }\end{array}$ \\
\hline
\end{tabular}




\section{CONCLUSION}

In this paper, we presented a review of the works of the authors for the period between (2010-2019) to identify the license plate and clarified the method of performance and methods used for each author so that we gave a brief description of the researchers' work and as a review and summary characterized by the work of the table that explains the methods and tests completed and each according to the year in which the research was completed. Experimental results for researchers between (2010-2019) in Table (1), it was found that the methods used achieved high results.

\section{REFERENCES}

[1] Nuzulha Khilwani Ibrahim, Emaliana Kasmuri, Norazira A Mohamad Riduwan Md Nawaw "License Plate Recognition (LPR): A Review with Experiments for Malaysia Case Study", The International Journal of Soft Computing and Software Engineering [JSCSE], Vol. 3, No. 3, Special Issue.

[2] Kuo Ming Hung, Ching Tang Hsieh ," A Real-Time Mobile Vehicle License Plate Detection and Recognition”, Tamkang Journal of Science and Engineering, Volume:13, No. 4, Pages: 433-442, 2010.

[3] Mohsin, A., Hassin, A. H., and Abdul Jaleel, I. Q., "An Automatic Recognizer for Iraqi License Plates Using ELMAN Neural Network", Journal of Software Engineering and Applications, SciRes, Volume:3, No. 12, Pages. 1163-1166, December, 2010.

[4] XIN LI , "Vehicle License Plate Detection And Recognition”, M.Sc. Thesis, University of Missouri-Columbia, 2010.

[5] Kaushik Deb, Andrey Vavilin, Jung-Won Kim, and Kang-Hyun Jo, "Vehicle License Plate Tilt Correction Based on the Straight Line Fitting Method and Minimizing Variance of Coordinates of Projection Points", International Journal of Control, Automation, and Systems (2010) 8(5):975-984DOI 10.1007/s12555-010-0506-z ,http://www.springer.com/12555

[6] Petr Cika, Martin Zukal, and Miroslav Sebela, “Vehicle License Plate Detection and Recognition Using Symbol Analysis “978-1-4577-1411-5/11/\$26.00 @2011 IEEE.

[7] Muhammad H. Dashtban , Zahra Dashtban , Hassan Bevrani , "A Novel Approach for Vehicle License Plate Localization and Recognition ”,IEEE International Journal of Computer Applications Volume:26, No.11, Pages:0975 - 8887, 2011.

[8] Mehran Rasooli, Sedigheh Ghofrani, and Emad Fatemizadeh, " license plate detection and recognition for Iranian private cars", International Journal of Signal Processing, Image Processing and Pattern Recognition

Vol. 4, No. 1, March 2011.

[9] Khalid W. Maglad , “A Vehicle License Plate Detection and Recognition System”, Journal of Computer Science ISSN: 15493636 Volume: 8 Issue: 3 Pages: 310-315, 2012.

[10] Nada Najeel Kamal, "Iraqi License Plate Recognition System”, M.Sc. Thesis, College of science, Baghdad University , Iraq, 2013.

[11] Mr.Furat Nidhal Tawfeeq1, Mrs. Yasmine Mazin Tabra2, " Gate Control System for New Iraqi License Plate", Iraqi Commission for Computers \& Informatics (ICCI) Iraqi Journal for Computers and Informatics (IJCI), Vol (1) Issue (1), 2014 .

[12] Emad Mohammed Abod "Real Time System to Recognition of Iraqi License Plate for Vehicle Tracking" A thesis Submitted to the College of Science / Al Mustansiriyah University in partial fulfillment of the requirements for the degree of Master of Science in Computer Science, 2015.

[13] Dr. Eyad I. Abbas, Thaaer A. Hashim, "Iraqi Cars License Plate Detection and Recognition System using Edge Detection and Template Matching Correlation”, Eng. \&Tech.Journal, Vol. 43 Part (A) ,No.2 , 2016.

[14] Safaa S. Omran, Jumana A. Jarallah , “Iraqi Car License Plate Recognition Using OCR “, CIC-COCOS’17, March 29-30, 2017, Cihan University-Erbil .

[15] Jia Wang ${ }^{1} \&$ Boris Bacic ${ }^{1} \&$ Wei Qi Yan “' “An effective method for plate number recognition”, Springer Science+Business Media New York, DOI 10.1007/s11042-017-4356-z,2017.

[16] Ghassan Khazal Ali * ,"Developing Recognition System for New Iraqi License Plate” , ISSN: 1813-162X (Print) ; 23127589 (Online) Tikrit Journal of Engineering Sciences available online at: http://www.tj-es.com, 2018.

[17] Ira Kusumadewi, Christy Atika Sari, De Rosal Ignatius Moses Setiadi and Eko Hari Rachmawanto, " License Number Plate Recognition using Template Matching and Bounding Box Method”, IOP Conf. Series: Journal of Physics: Conf. Series 1201 
(2019) 012067,IOP Publishing , doi:10.1088/1742-6596/1201/1/012067, International Conference on Electronics Representation and Algorithm (ICERA 2019).

[18] jianzong wang,1xinhui liu,2aozhi liu2 and jing xiao3, "A deep learning-basedmethod for vehicle license plate recognition in natural scene", (http://creativecommons.org/licenses/by/4.0/), doi:10.1017/ATSIP.2019.9,

vol. 8, e16, page 1 of 7 c The Authors, SIP (2019). 